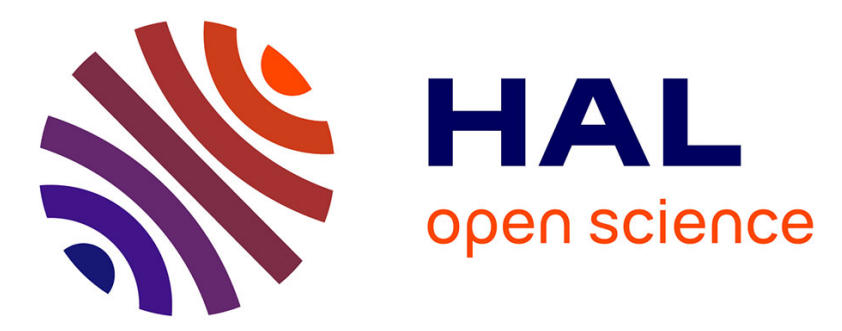

\title{
the moderating role of seeking social support on coping styles and perceptions of organizational justice: a study with french and turkish students
}

Rémi Finkelstein, Jale Minibas-Poussard, Marina Bastounis

\section{- To cite this version:}

Rémi Finkelstein, Jale Minibas-Poussard, Marina Bastounis. the moderating role of seeking social support on coping styles and perceptions of organizational justice: a study with french and turkish students. Social behavior and personality, In press, 37 (6), pp.845-865. hal-01615530

\author{
HAL Id: hal-01615530 \\ https://hal.science/hal-01615530
}

Submitted on 13 Oct 2017

HAL is a multi-disciplinary open access archive for the deposit and dissemination of scientific research documents, whether they are published or not. The documents may come from teaching and research institutions in France or abroad, or from public or private research centers.
L'archive ouverte pluridisciplinaire HAL, est destinée au dépôt et à la diffusion de documents scientifiques de niveau recherche, publiés ou non, émanant des établissements d'enseignement et de recherche français ou étrangers, des laboratoires publics ou privés. 


\title{
THE MODERATING ROLE OF SEEKING SOCIAL SUPPORT ON COPING STYLES AND PERCEPTIONS OF ORGANIZATIONAL JUSTICE: A STUDY WITH FRENCH AND TURKISH STUDENTS
}

\author{
RÉMI FINKELSTEIN \\ University Paris West, La Defence, France \\ JALE Minibas-PoussaRd \\ Galatasaray University, Istanbul, Turkey \\ MARINA BASTOUNIS \\ University Paris Descartes, Rouen Business School, France
}

\begin{abstract}
We examined the relationship between perceived organizational justice and coping styles in a cross-cultural comparison. Data were collected from university students in Paris, France (individualist culture; $N=192$, age $M=21.6$ ) and Istanbul, Turkey (collectivist culture; $N$ = 251, age $M=22$ ). The questionnaire (adapted from Colquitt, 2001) included ratings of distributive, procedural, and interactional justice at the university, and a coping style inventory (Vitaliano, Russo, Carr, Maiuro, \& Becker, 1985) measuring preference for problem-focused coping, emotion-focused coping and seeking social support. In the Turkish data social-support seeking was higher than in the French sample and it was positively correlated with justice perceptions. When seeking social support was linked to problem-focused coping, it was also linked to a more positive evaluation of justice in the Turkish, but not the French data.
\end{abstract}

Keywords: distributive justice, procedural justice, interactional justice, informational justice, coping styles.

The term organizational justice refers to perceptions of fairness and evaluations concerning the appropriateness of workplace outcomes or processes (Greenberg

Rémi Finkelstein, PhD, Psychology Department, University Paris West, La Defence, France; Jale Minibas-Poussard, PhD, Business Administration Department, Galatasaray University, Istanbul, Turkey; Marina Bastounis, PhD, Rouen Business School, University Paris Descartes, France.

Appreciation is due to anonymous reviewers.

Please address correspondence and reprint requests to: Rémi Finkelstein, PhD, University Paris 10, Psychology Department, 200, avenue de la République, Nanterre 92001, Cedex, France. Phone: +33(0)1 409778 11; Fax: +33(0)1 409771 58; Email: remifinkelstein@gmail.com 
\& Cropanzano, 2001). It is related to four main components: distributive justice (Adams, 1965), describing the perceived equity in rewards and contributions between oneself and others; procedural justice (Thibaut \& Walker, 1975), describing the criteria applied during the decision-making process; interactional justice, describing relations between superiors and employees; and informational justice, describing the availability of information (Bies \& Moag, 1986; Greenberg, 1993).

The consequences of perceptions of (in)justice on human behavior have received much attention in organizational literature in recent years (Greenberg \& Colquitt, 2005; Greenberg \& Cropanzano, 2001). The four components of perceived justice have been validated empirically (Colquitt, Conlon, $\mathrm{Ng}$, Wesson, \& Porter, 2001), and the issues surrounding the cross-cultural variability of justice norms and perceptions are of key importance in the literature (Gilliland, Steiner, \& Skarlicki, 2001; Morris \& Leung, 2000). This trend may be related to the growing interest in the effects of globalization that drive increasing levels of competitiveness requirements. The current job market is characterized by high uncertainty and employees seem to be becoming increasingly sensitive to issues related to injustice (Van den Bos, Heuven, Burger, \& van Veldhuizen, 2006; Yamaguchi, 2005). The sphere of higher education follows these developments and most students strive to complete their academic qualifications in reputable universities around the world. International competition between universities and business schools is amplified and the ranking system according to standards of scientific production also participates in this phenomenon (Cai Liu, 2007). The European Erasmus student exchange program, through which students in the European Union obtain credit from universities abroad, is a prime example of the move towards globalization of higher education. In this light, the level of difficulty in adapting to new cultural norms within the host university is central to the success of international student mobility. The authors of the present study focused on perceptions of organizational justice in the university setting with a sample of students from France and Turkey. Sampling took place in Paris, France and Istanbul, Turkey. Hofstede's classification of national cultures (Hofstede, 1980, 2003) describes France and Turkey as highly similar cultures in all dimensions (Power Distance Index France $=68$, Turkey $=66$; Masculinity Index France $=43$, Turkey $=45$; Uncertainty Avoidance Index France $=86$, Turkey $=$ 85) except one: individualism. Turkey scores much lower (Individualism Index =37) than France (Individualism Index $=71$ ), meaning that, in Turkish society individuals are integrated into strong, cohesive ingroups, while in French society, ties between individuals seem looser and generally everyone is expected to look after him/herself. A primary aim of this study was to compare students from a Western/individualistic culture with those from an Eastern-Oriental/collectivistic culture, in an attempt to add to the growing literature examining organizational 
justice from a cross-cultural perspective (Beugré, 2007; Gilliland, Steiner, \& Skarlicki, 2001; Leung, 2005).

The present study was also designed to investigate perceived organizational justice seen in terms of perceived stress (Greenberg, 2004; Spector \& Miles, 2001; Vermunt \& Steensma, 2005), focusing on the positive or negative relationship that adopted coping styles may have with evaluations of perceived organizational justice. Since culture has both direct effects on perceptions of justice and moderator effects on reactions to perceived injustice (see Beugré, 2007), from a perspective of cultural integration it is important to establish if, and to what degree of efficacy, students of different cultural origins use the same forms of adjustment to perceived (in)justice in the academic system. In the present study the focus was on one mechanism of adjustment and coping, namely social-support seeking, which is susceptible to difference in cultures that are more or less individualistic, as is the case with French and Turkish cultures. More specifically, the third aim of this study was to examine the possible moderating role that seeking social support may play in the perceptions of organizational justice, in terms of the other coping styles that it may be associated with (emotion-focused or problem-focused coping.)

\section{Coping Styles and Stress: The Pivotal Role of Social-Support SEEKING}

Lazarus and Folkman (1984) contributed a key model to the domain covering the relationship between stress and coping styles. According to this model, individuals make two appraisals of events: the first involves an assessment of whether events affect the individual's wellbeing; the second concerns the determination of whether a threat exceeds the individual's coping capabilities. A stressful environment can, thus, be experienced as more or less threatening depending on individuals' coping strategies. Lazarus and Folkman identified two broad categories of coping strategies: one focused on problem resolution and the other centered on regulating emotions. Several more coping strategies have been examined and placed in one of these two categories, for instance, social-support seeking, avoidance, resignation, positive thinking, or proactive attitude (see Greenglass, Fiksenbaum, \& Eaton 2006). Among coping styles, seeking social support moderates several stressors on wellbeing in the workplace: it contributes to the reduction of work-family conflict (van Daalen, Willemsen, \& Sanders, 2006), positively moderates the relationship between self-efficacy and perceived stress (Stetz, Stetz, \& Bliese, 2006), protects from stress and leads to greater use of proactive coping styles (Snow, Swan, Raghavan, Connel, \& Kleines, 2003) and increases efficacy in the resistance to psychological distress at work (Shimatzu \& Shutarou, 2003). 
Seeking social support seems to play a particular and pivotal role among these coping styles, in that it can be focused on action or emotions depending on what individuals actually look for when they seek social support: which may be either help in taking action to solve their problem, or support in managing their emotions (Folkman \& Lazarus, 1991). Recently, a survey of 223 New York police officers carried out by Patterson (2003) demonstrated that social support and problem-focused coping had the same buffering effect for feelings of distress in professional life, which was not the case when social support was associated with emotion-focused coping styles. In other words, social-support seeking may lead to both positive or negative attitudes and behaviors in terms of the other coping styles it is associated with.

In a study by Trocki and Orioli (1994) the differential effectiveness of social support in response to professional stress was illustrated. In this study the authors explain that men experience less stress than women in business because men seek social support in their professional network while women seek support in their family and friends network, which accentuates the perceived conflict between their professional activities and commitments and their family life.

Given the central role of social support in student life (including group assignments, informal exchanges, help in catching up with work) it is important to clarify the terms of its effectiveness.

To this end, the aim in this study was to test the general assumption that students who use the strategy of social-support seeking would evaluate organizational justice in their university differently if they associated social support with emotion-focused vs. problem-focused coping. We expected that the pivotal role of social-support seeking would be statistically expressed as the moderator of the relationship between perceived organizational justice and coping styles.

\section{Cross-Cultural Variation in Coping Strategies}

Comparisons of strategies of coping with stress across Western and Eastern cultures are rare in the relevant literature. Spector, Cooper, and Poelmans (2004) compared China, several Western, and South American countries on measures of stress in relation to the work-family conflict. The authors reported a positive link between marital status, number of children and organizational wellbeing in all its aspects that was observable only in China. The literature comparing East and West on measures of work locus of control and its consequences for stress is richer and studies concur that internal vs. external locus of control is a key factor in the management of work-related stress. Individuals with an internal locus of control (i.e., those who believe that what happens to them depends on their own actions and not on chance, external forces, or powerful others) experience less burnout and distress at work (Spector, 1986). Conversely, individuals with an external locus of control (i.e., those who believe that what happens to them 
depends mostly on chance, external forces, or powerful others) are less satisfied with their career and are more frequently ill (Evers, Frese, \& Cooper, 2000). As was discussed by Greenberg (2004), the impact of procedural justice, and therefore interactional justice, is linked to individuals' need for control (Thibaut \& Walker, 1975). According to Spector, Sanchez, Siu, Salgado, and Ma (2004), individuals in Eastern cultures generally believe that while they cannot personally control their environment, they can achieve some level of control through social relations. This is an important distinction that highlights the socially shared character of the feeling of control related to stress in Eastern cultures, which is central to coping through seeking social support.

University student samples have frequently been used in the study of coping styles, as they are considered to be a population that faces a lot of stress. Coping strategies in students have been analyzed, particularly in situations of crosscultural transition. Bailey and Dua (1999) tested the assumption that culture mediates coping styles activated to face acculturative stress in Asian students newly arrived in Australia. The results verified that Asian students tended to employ collectivist coping strategies and Anglo-Australians tended towards the use of individualist coping styles. Essau and Trommsdorff (1996) conducted a survey with North American, Malaysian, and German undergraduate students and found that in dealing with academic problems, Malaysian students most often used emotion-focused coping, but experienced the most physical symptoms of stress.

Recently, Gençöz, Gençöz, and Bozo (2006) examined the hierarchical dimensions of coping styles in a Turkish student sample and revealed that the first two dimensions were problem-focused coping and emotion-focused coping. The third dimension consisted of items related to seeking social support, implying the presence and importance of an indirect coping style.

On the basis of the above and given the importance of social support in oriental cultures (Spector, Sanchez, Siu, Salgado, \& Ma 2004) we expected that the use of social support by Turkish students would be linked to higher ratings of organizational justice than would be the case for French students.

\section{Coping Styles, Stress, and Organizational Justice}

Recent developments in the field of organizational psychology tend to describe perceptions of injustice as a key stress agent, provoking individual reactions similar to those of coping strategies described in the literature on stress (Greenberg, 2004; Spector \& Miles, 2001; Zellars, Liu, Bratton, Brymer, \& Perrewé, 2004). Folkman and Moskowitz (2004) underline that "Coping responses are thus initiated in an emotional environment, and often one of the first coping tasks is to down-regulate negative emotions that are stressful in and of themselves and may be interfering with instrumental forms of coping" (p. 747). 
Cropanzano, Weiss, Suckow, and Grandey (2000), proposed an integrative model of emotions related to injustice and described a two-step process resembling the one proposed by Lazarus and Folkman (1984). In the first step, when the individual feels strong negative emotions, the perceived injustice functions like an alarm, triggering the evaluation of the elements of the situation, and in particular the just or unjust nature of procedures. Since the direct expression of negative emotions does not comply with organizational norms, individuals then become engaged in a second step, which consists either of using different strategies to mask their emotions, or of reacting directly to the source of the problem. The authors of this model showed that these strategies become more costly for employees who use an emotion-focused coping strategy. Recently, Greenberg (2004) presented a three-stage model according to which the stress perceived by employees increases with successive evaluations of the three types of justice: distributive, procedural, and interactional. In a similar perspective, Judge and Colquitt (2004) demonstrated that the implementation of familysensitive policies in the organization improved the relations between stress and the work vs. family conflict, and activated a stronger feeling of organizational justice. The available evidence on coping styles now offers important theoretical and practical perspectives on the more or less stable nature of these strategies in individuals (Havlovic \& Keenan, 1995; Koeske, Kirk, \& Koeske, 1993) and on their more or less adapted nature (Ben-Zur \& Yagil, 2005; De Jong \& Emmelkamp, 2000). However, little information is available on the direct influence of using certain coping strategies on the perceptions of organizational justice. To the best of our knowledge, only the work of Zellars et al. (2004) presents results obtained in this domain of investigation. In their study these authors showed that employees who reacted to procedural justice with avoidance strategies also manifested stronger turnover intention.

In our view, one possible explanation for this phenomenon is that the vast majority of research conducted in the area uses organizational justice as an independent variable (see the meta-analysis conducted by Colquitt et al., 2001; and Van den Bos \& Lind, 2002), not as a dependent variable, as we did in the present study. The line of reasoning followed in our study is that coping styles can been considered as an intrapersonal variable, likely to moderate perceptions of justice in the same way as emotions (Van den Bos, 2003) or certain personality traits do (Colquitt, Scott, Judge, \& Shaw, 2006). Specifically, we believed that merely involving social support in a style of coping focused on problem solving allows individuals to improve their perceptions of justice, which is not the case when social support is associated with coping focused on emotions. In doing so, we focused on what Van den Bos and Lind (2002) called the "why and how" of perceptions of justice, issues on which, according to these authors, little knowledge is available. Shedding new light on the impact of interindividual 
differences (i.e., coping styles) in perceptions of justice in the present study we attempted to contribute to the research on the "why and how" of justice perceptions.

Given the proactive nature of coping focused on problem resolution we expected to find a positive relationship between this type of coping and ratings of perceived justice. Conversely, because emotion regulation may be costly and inefficient in an organizational context (Cropanzano et al., 2000) we expected to find a negative relationship between coping focused on emotions and justice ratings. Finally, given the contextual nature of organizational justice and the collective implications of perceived (in)justice for individual reactions (Kray \& Lind, 2002), we expected in this study that social-support seeking would play an important moderating role in the relationship between organizational justice perceptions and the two other forms of coping, that is, coping focused on emotions and problem resolution. Based on the literature discussed above (Cropanzano et al., 2000; Folkman \& Lazarus, 1991; Patterson, 2003) we expected that seeking social support would positively moderate the relationship between perceived (in)justice and problem-focused coping, and that it would not moderate (reduce) the negative relationship between perceived (in)justice and emotion-focused coping.

In sum, the following hypotheses were tested:

H1: Based on Hofstede's description of cultural dimensions (1980, 2003), Turkish students (collectivist culture) would be more likely to use a coping style focused on seeking social support than would French students (individualist culture).

H2: Taking into account the proactive nature of problem-focused coping we expected that this would be linked to positive perceptions of justice.

H3: Since emotion regulation may be costly and ineffective as a coping strategy (Cropanzano et al., 2000) we expected emotion-focused coping to be linked to negative perceptions of organizational justice.

H4: Given the important positive role of social support in Eastern cultures (Spector, Sanchez, Siu, Salgado, \& Ma, 2004), we expected a moderating effect of culture (France vs. Turkey) according to which social support would have stronger links with positive perceptions of justice in the Turkish than in the French sample.

H5: Since the positive or negative effects of seeking social support depend on the end purpose that this support aims to serve (Folkman \& Lazarus, 1991; Patterson, 2003) it was expected that social-support seeking would positively moderate the relationship between perceived organizational justice and problem-focused coping. 


\section{METHOD}

\section{SAMPLe}

Data collection was carried out at the University of Paris X in France $(n=192)$ and in Galatasaray University in Turkey $(n=251)$. Mean age was 22 years in the Turkish sample and 21 years 6 months in the French sample. Thirty-five percent of the Turkish sample and $46 \%$ of the French sample was male.

\section{MeAsures}

The questionnaire presented to participants included an organizational justice scale adapted from the instrument developed by Colquitt (2001) for use in an academic context, a coping-style inventory developed by Vitaliano, Russo, Carr, Maiuro, and Becker (1985) and validated in France by Cousson, BruchonSchweitzer, Quintard, Nuissier, and Rascle (1996). All translated instruments were backtranslated to control for the quality (Turkish and French) by independent bilingual individuals. The scales showed satisfactory properties in both versions.

The organizational justice scale is composed of four subscales rated from 1 to 5, where high scores indicate high perceived justice: (i) the distributive justice subscale, composed of 4 items, example item: "To what extent were your grades proportional to your work?" (Cronbachs's $\alpha$ France $=.82$; Turkey $=.85$ ); (ii) the procedural justice subscale, a 7-item scale, example item: "To what extent was the grading evaluation system consistent?" (Cronbach's $\alpha$ France $=.67$; Turkey $=.79$ ); (iii) the interactional justice subscale, composed of 4 items, example item: "To what extent were your professors polite with you?" (Cronbach's $\alpha$ France = .77 ; Turkey $=.81$ ); (iv) the informational justice subscale with 4 items, example item: "To what extent did your professors explain their grading system?" $($ Cronbach's $\alpha$ France $=.76$; Turkey $=.83$ ).

The coping style inventory is composed of three subscales rated from 1 to 4 where high scores indicate preference for this coping strategy: (i) the problem-focused coping style subscale composed of 10 items, example item: "I challenge to obtain what I want." (Cronbach's $\alpha$ France $=.67$; Turkey $=.74$ ); (ii) the emotion-focused coping style with 9 items, example item: "I hope for a miracle." (Cronbach's $\alpha$ France $=.61$; Turkey $=.59$ ); (iii) the scale measuring coping focused on seeking social support, composed of 8 items, example item: "I try to talk with someone who can solve my problem." (Cronbach's $\alpha$ France $=.52$; Turkey $=.54$ ). While the Cronbach coefficients of the two last scales are small, they remain above the threshold suggested by Nunnally and Bernstein (1994). 


\section{RESULTS}

\section{Cross-National Comparisons}

In comparing the samples, two components of organizational justice were found to be significantly different from each other: both distributive justice $F(1$, $437)=3.58, p \leq .05$, and interactional justice scores, $F(1,438)=7.62, p \leq .05$, were higher in the French students' data (see Table 2). No significant differences emerged in the problem-coping and emotion-coping scores, but as predicted in Hypothesis 1, Turkish respondents scored significantly higher than the French on seeking social support, $F(1,431)=22.23, p \leq .001$.

TABLE 1

Comparison of Means for the Turkish and French SAMples for all the Variables

\begin{tabular}{lcccc}
\hline & France $M$ & Turkey $M$ & $d f$ & $F$ \\
\hline 1. Distributive justice & 11.69 & 11.05 & $(1,437)$ & $3.58^{*}$ \\
2. Procedural justice & 18.88 & 18.81 & $(1,426)$ & 0.02 \\
3. Interactional justice & 15.11 & 12.44 & $(1,438)$ & $58.11^{* *}$ \\
4. Informational justice & 10.56 & 11.10 & $(1,437)$ & 2.28 \\
5. Problem-focused coping & 29.18 & 29.53 & $(1,427)$ & .78 \\
6. Emotion-focused coping & 23.06 & 23.45 & $(1,428)$ & 1.00 \\
7. Seeking social support & 21.82 & 23.71 & $(1,431)$ & $22.23^{* *}$ \\
\hline
\end{tabular}

${ }^{*} p \leq .05 ;{ }^{* *} p<.001$

\section{Correlational Analyses}

The results of the correlational analyses are shown in Table 2 for the Turkish sample and in Table 3 for the French sample. The four components of organizational justice were all intercorrelated in results for the Turkish sample. Only procedural, interactional and informational justice scores were intercorrelated in results for the French sample.

TABLE 2

Correlations in the Turkish SAMPle

\begin{tabular}{lcccccc}
\hline & 1 & 2 & 3 & 4 & 5 & 6 \\
\hline 1. Distributive justice & & & & & & \\
2. Procedural justice & $.42^{*}$ & & & & & \\
3. Interactional justice & $.23^{*}$ & $.51^{*}$ & & & & \\
4. Informational justice & $.27^{*}$ & $.33^{*}$ & $.37^{*}$ & & & \\
5. Problem-focused coping & .06 & $.18^{*}$ & $.17^{*}$ & .09 & & \\
6. Emotion-focused coping & -.06 & -.07 & -.05 & -.12 & -.06 & \\
7. Seeking social support & .05 & $.19^{*}$ & $.17^{*}$ & .10 & $.29^{*}$ & $.16^{*}$ \\
\hline${ }^{*} p \leq .01$ & & & & & &
\end{tabular}


Coping style correlates differed in the two data sets. In the Turkish sample, problem-focused coping and seeking social support ratings were positively correlated with procedural $(r=.18$ and $r=.19$ respectively, $p \leq .01)$ and interactional justice ratings ( $r=.17$ and $r=.17$ respectively, $p \leq .01$ ). In addition, as predicted by Hypothesis 2, problem-focused coping significantly predicted procedural justice $\left(R=.17, R^{2}=.03, F=7.35, \beta=.17, p \leq .01\right)$ and interactional justice ratings $\left(R=.16, R^{2}=.02, F=6.73, \beta=.16, p \leq .01\right)$. In the French sample, no correlations were observed in the data among problem-focused coping, social support seeking and justice perceptions.

TABLE 3

Correlations in the French Sample

\begin{tabular}{lcccccc}
\hline & 1 & 2 & 3 & 4 & 5 & 6 \\
\hline 1. Distributive justice & & & & & & \\
2. Procedural justice & $.19^{*}$ & & & & & \\
3. Interactional justice & .08 & $.21^{*}$ & & & & \\
4. Informational justice & .12 & $.31^{*}$ & $.42^{*}$ & & & \\
5. Problem-focused coping & -.02 & -.09 & .001 & .07 & & \\
6. Emotion-focused coping & $-.22^{*}$ & $-.20^{*}$ & $-.22^{*}$ & -.13 & .02 & \\
7. Seeking social support & .03 & .04 & .001 & .03 & $.34^{*}$ & $.19^{*}$ \\
\hline
\end{tabular}

${ }^{*} p \leq .01$

In the French sample, emotion-focused coping was negatively correlated with organizational justice ratings (distributive, $r=-22$; procedural, $r=-.20$; interactional, $r=-22 ; p \leq .01)$. In addition, as predicted by Hypothesis 3, emotion-focused coping scores significantly predicted distributive justice $(R=$ $\left..22, R^{2}=.04, F=9.45, \beta=-.22, p \leq .01\right)$, procedural justice $\left(R=.20, R^{2}=.04\right.$, $F=3.56, \beta=-.20, p \leq .01)$, and interactional justice ratings $\left(R=.22, R^{2}=.04, F\right.$ $=9.45, \beta=-.22, p \leq .01)$.

\section{Moderation EFFects}

The moderation effect of culture on the relationship between justice perception and social-support seeking was examined in order to test Hypothesis 4. Perceived procedural justice was significantly related to social-support seeking $(R=.19$, $\left.R^{2}=.03, F=9, \beta=.19, p \leq .01\right)$ but not to culture. Furthermore, the interaction between social-support seeking and culture was significant $\left(R=.13, R^{2}=.01, F\right.$ $=4, \beta=.14, p \leq .01$ ). Simple slopes analysis was conducted to further analyze this interaction. In the case of the Turkish students, procedural justice was significantly and positively related to social support seeking. This relationship was not found when we looked at the case of the French students (see Figure $1)$. 


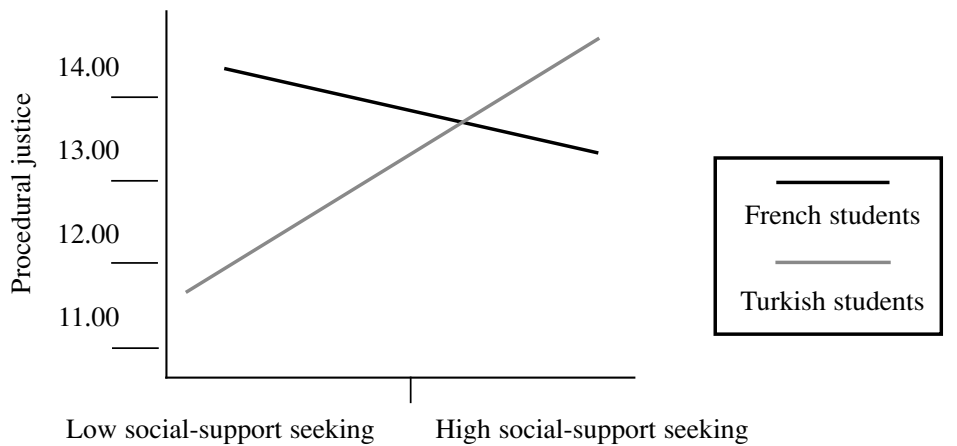

Figure 1. Moderation effect of culture on the relationship between seeking social support and perceived procedural justice.

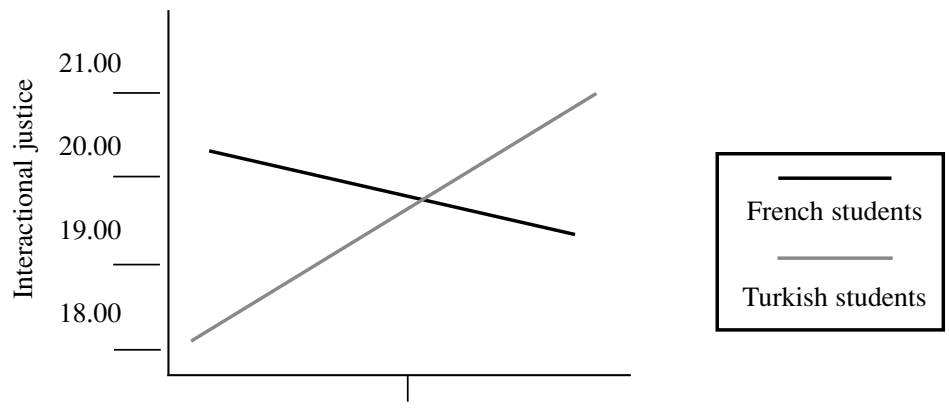

Low social-support seeking High social-support seeking

Figure 2. Moderation effect of the culture on the relationship between seeking social support and perceived interactional justice.

Similarly, interactional justice was significantly related to social-support seeking $\left(R=.36, R^{2}=.12, F=31, \beta=.35, p \leq .001\right)$ but not to culture. Furthermore the interaction between social-support seeking and culture was significant $\left(R=.16, R^{2}=.02, F=6.73, \beta=.11, p \leq .01\right)$. Simple slopes analysis was conducted to further analyze this interaction. In the case of the Turkish students interactional justice was significantly and positively related to socialsupport seeking. This relationship was not found when we looked at the case of French students (see Figure 2).

We tested the data for a moderating effect of seeking social support on the relationships between justice perceptions and problem-focused coping as predicted in Hypothesis 5. In the data for the Turkish students, the interaction between social support seeking and problem-focused coping was significant. When seeking social support was high (one $S D$ above the mean), the relationship 
between problem-focused coping and procedural justice was significant $(R=.39$, $R^{2}=.15, F=3.4, \beta=.40, p \leq .05$; see Figure 3 ) but when scores for seeking social support were low (one $S D$ below the mean) it was not. In other words, when a high social-support seeking score was combined with a high problem-focused coping score, it had a positive effect on perceived justice scores. This relationship was not found in the data for the French students.

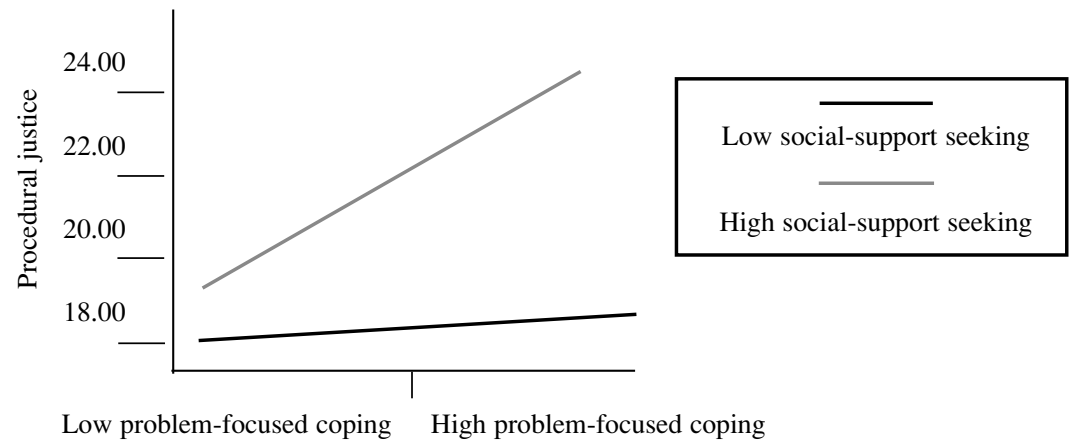

Figure 3. Moderation effect of seeking social support on the relationship between problem-focused coping and perceived procedural justice (Turkish sample).

No interaction was observed between emotion-focused coping, seeking social support, and perceived justice. But simple slopes analyses indicated that socialsupport seeking negatively moderated the relationship between emotion-focused coping and perceived justice in both cultures. In other words, when seeking social support was high (one $S D$ above the mean), emotion-focused coping and interactional justice were negatively correlated but not when seeking social support was low.

In sum, the findings demonstrated that seeking social support was a strategy used more by Turkish than by French participants in our study. For the Turkish sample, high scores in seeking social support were more often related to a positive perception of organizational justice than low scores. This difference was not observed in the data from the French participants. In addition, the moderating role of seeking social support differed in the two cultures when it was associated with problem-focused coping. Under these conditions, it was related to positive perceptions of organizational justice for the Turkish sample but not for the French.

\section{DISCUSSION}

Our study was a test of the role of three generic forms of coping in relation to the perceptions of organizational justice and compared two samples from cultures 
with a higher (France) vs. lower (Turkey) individualism index as described in Hofstede's work (1980, 2003). While several of our hypotheses were confirmed, several unexpected results are particularly noteworthy in the making of practical recommendations and designing future research projects.

Hypothesis 1 postulated a stronger preference for coping focused on seeking social support in the Turkish (collectivist) than the French (individualist) sample and this was confirmed by the data. This result also corroborates Hofstede's analyses, which suggest that Eastern societies resort more to collectivistic values and tend to seek more control over social relationships (Spector, Sanchez, Siu, Salgado, \& Ma, 2004). Hypothesis 2 predicted a positive relationship between problem-focused coping and justice perceptions and this was supported by the Turkish but not the French data. Hypothesis 3 predicted a negative relationship between emotion-focused coping and justice perceptions and this was supported by the French but not the Turkish data.

The data tend to support Hypothesis 4, predicting a moderating effect of culture (France vs. Turkey) on the relationship between seeking social support and perceived justice. In fact, according to our results, social support was related more strongly to a positive perception of organizational justice in the Turkish students than in the French students. Along with the findings supporting Hypothesis 1, the evidence of a moderating effect of culture also underlines the potentially differentiating and beneficial effects that seeking social support may have on how an organization is perceived.

Finally, Hypothesis 5 was supported by the Turkish but not the French data. In fact, seeking social support positively moderated the relationship between perceived justice and problem-focused coping for the Turkish but not the French students. These findings clearly support the argument of Folkman and Lazarus (1991) and Patterson (2003) that the role of seeking social support depends on the objective of this support, that is, either to solve the problem or to manage emotions.

Beyond the influence of culture, an additional contextual factor may be related to the interpretation of the present results, that is, the admission systems in the universities where sampling took place. French universities admit students from a wide socioeconomic and cultural spectrum without any specific admission requirement beyond having a high school qualification (see Guimond, 1998), while Turkish students enter the university on the basis of their performance in a very demanding entrance examination (Turkish Association of Education, 2005). One consequence of this system is that the population of Turkish students is much more homogeneous than that of French students. The majority of Turkish university students come from the middle and upper-middle socioeconomic classes where families actively support values related to obtaining a higher education (Ogawa \& Tansel, 2005). In many ways, selection in the French 
universities takes place over the first two years of the degree course, when a large number of students fail or drop out, making access to the final stage of study to qualify for a degree, difficult and uncertain. In a recent OECD report (2006) on higher education, Turkey ranks among the lowest in terms of numbers who achieve access to university studies, and the highest among number of students who obtain their degree or diploma. Conversely, France is ranked as a country with a high level of accessibility to university studies, and very low in the number of students who actually graduate. Ogawa and Tansel also found that in the Turkish system of higher education, the majority of students who achieve entrance also end up graduating with their degree and have a much greater chance of getting a job.

It is possible that these demographic and structural factors are related to the development of a dissimilar system of expectations in the samples we studied. French students are in a system where it is very uncertain that they will ever graduate, and this may also explain their tendency to resort to emotion-focused coping styles which affect their evaluation of the university. This factor may also explain why these students do not prefer the activation of a more proactive coping strategy. Similarly, the fact that Turkish students resort more frequently to seeking social support may also be explained by the greater sociocultural homogeneity of the student population, which involves more plentiful resources of intra-group solidarity and communication. In order to elucidate these interpretations, a future study should include a sample from private French universities with a selective admission procedure. Such a comparison should clarify whether or not the present results are due to cultural differences reflected in different strategies of coping with organizational justice in higher education institutions, or to different systems of admission giving rise to different expectations linked to the sociodemographic composition of the university populations.

One recommendation that we may extrapolate from the results of our study relates to the pedagogical practice in European universities of assigning group work and individual tutoring to support successful learning. When the systematic use of work groups is not backed up by specific instructions on the objectives of this type of support, group work often leads to counterproductive conflicts and relative lassitude. However, adequate preparation of the group with specific description of working objectives and the means to attain them, which always serves to increase motivation and supports group performance, should also reduce the negative emotional charge linked to the representations of the group and individuals' experiences with the university organization (Locke \& Latham, 2002). This should be even truer of foreign students, whose cultural horizon is very different from that of the host university and whose apprehension about the judgement of others could be amplified through lack of information concerning the available forms of support or group work. 
Finally our findings regarding the pivotal role of seeking social support invite a number of questions to be answered in future projects. Of particular interest would be testing the more or less adapted function of seeking social support in different situations when individuals mobilize a proactive, problem-focused vs. an emotion-focused coping style.

\section{REFERENCES}

Adams, J. S. (1965). Inequity in social exchange. In L. Berkowitz (Ed.), Advances in experimental social psychology (Vol. 2, pp. 267-299). New York: Academic Press.

Bailey, F. J., \& Dua, J. (1999). Individualism-collectivism, coping styles, and stress in international and Anglo-Australian students: A comparative study. Australian Psychologist, 34(3), 177-182.

Beugré, C. D. (2007). A cultural perspective of organizational justice. Charlotte, NC: Information Age Publishing.

Ben-Zur, H., \& Yagil, D. (2005). The relationship between empowerment, aggressive behavior of customers, coping and burnout. European Journal of Work and Organizational Psychology, 14(1), 81-99.

Bies, R. J., \& Moag, J. F. (1986). Interactional justice: Communication criteria of fairness. In R. J. Lewicki, B. H. Sheppard, \& M. H. Bazerman (Eds.), Research on negotiations in organizations (Vol. 1, pp. 43-55). Greenwich, CT: JAI Press.

Cai Liu, N. (June 2007). Academic ranking of world universities: Methodologies and problems. Shanghai, China: Jia Tong University.

Colquitt, J. (2001). On the dimensionality of organizational justice: A construct validation of a measure. Journal of Applied Psychology, 86(3), 386-400.

Colquitt, J. A., Conlon, D. E., Ng, K. Y., Wesson, M. J., \& Porter, O. L. H. (2001). Justice at the millennium: A meta-analytic review of 25 years of organizational justice research. Journal of Applied Psychology, 86(3), 425-445.

Colquitt, J. A., Scott, B. A., Judge, T. A., \& Shaw, J. C. (2006). Justice and personality: Using integrative theories to derive moderator effects. Organizational Behavior and Human Decision Processes, 100(1), 110-127.

Cousson, F., Bruchon-Schweitzer, M., Quintard, B., Nuissier, J., \& Rascle, N. (1996). Analyse multidimensionnelle d'une échelle de coping: Validation française de la WCC-R (Ways of Coping Checklist Revised). Psychologie Française, 41(2), 155-164.

Cropanzano, R., Weiss, H. M., Suckow, K. J., \& Grandey, A. A. (2000). Doing justice to workplace emotion. In N. M. Ashkanas, C. E. J. Härtel, \& W. J. Zerbe (Eds.), Emotions in the work place: Research, theory, and practice (pp. 49-62). Westport, Connecticut/London: Quorum Books.

De Jong, G. M., \& Emmelkamp, P. M. G. (2000). Implementing a stress management training: Comparative trainer effectiveness. Journal of Occupational Health Psychology, 5(2), 309-320.

Essau, C. A., \& Trommsdorff, G. (1996). Coping with university-related problems: A cross-cultural comparison. Journal of Cross-Cultural Psychology, 27(3), 315-328.

Evers, A., Frese, M., \& Cooper, C. L. (2000). Revision and further developments of the Occupational Stress Indicator: LISREL results from four Dutch studies. Journal of Occupational and Organizational Psychology, 73(2), 221-240.

Folkman, S., \& Lazarus, R. S. (1991). Coping and emotion. In A. Monat \& R. S. Lazarus (Eds.), Stress and coping: An anthology (pp. 207-227). New York: Columbia University Press.

Folkman, S., \& Moskowitz, J. T. (2004). Coping: Pitfalls and promise. Annual Review of Psychology, 55, 745-774. 
Gençöz, F., Gençöz, T., \& Bozo, Ö. (2006) Hierarchical dimensions of coping styles: A study conducted with Turkish university students. Social Behavior and Personality: An international journal, 34(5), 525-534.

Gilliland, S., Steiner, D. D., \& Skarlicki, D. P. (2001). Theoretical and cultural perspectives on organizational justice. Greenwich, CT: Information Age Publishing.

Greenberg, J. (1993). The social side of fairness: Interpersonal and informational classes of organizational justice. In R. Cropanzano (Ed.), Justice in the workplace: Approaching fairness in human resource management (pp. 79-103). Hillsdale, NJ: Erlbaum.

Greenberg, J. (2004). Stress fairness to fare no stress: Managing workplace stress by promoting organizational justice. Organizational Dynamics, 33(4), 352-366.

Greenberg, J., \& Colquitt, J. A. (2005). Handbook of organizational justice. Mahaw, NJ: Lawrence Erlbaum Associates.

Greenberg, G., \& Cropanzano, R. (2001). Advances in organizational justice. Stanford: University Press.

Greenglass, E., Fiksenbaum, L., \& Eaton, J. (2006). The relationship between coping, social support, functional disability and depression in the elderly. Anxiety, Stress, and Coping, 19(1), 15-31.

Guimond, S. (1998). Processus de socialization dans l'enseignement supérieur: Le pouvoir de la connaissance [Socialization processes in higher education: The power of knowledge]. In J-L. Beauvois, R-V. Joule, \& J-M. Monteil (Eds.), 20 ans de psychologie sociale expérimentale francophone [20 years of French experimental social psychology] (pp. 231-273). Grenoble: Presses Universitaires de Grenoble.

Havlovic, S. J., \& Keenan, J. P. (1995). Coping with work stress: The influence of individual differences. In R. Crandall \& P. L. Perrewé (Eds.), Occupational stress: A handbook (pp. 179192). Washington DC: Taylor \& Francis.

Hofstede, G. (1980). Culture's consequences: International differences in work-related values. Newbury Park, CA: Sage.

Hofstede, G. (2003). Culture's consequences, comparing values, behaviors, institutions, and organizations across nations. Newbury Park, CA: Sage.

Judge, T. A., \& Colquitt, J. A. (2004). Organizational justice and stress: The mediating role of workfamily conflict. Journal of Applied Psychology, 89(3), 395-404.

Koeske, F. G., Kirk, S., \& Koeske, R. D. (1993). Coping with job stress: Which strategies work best? Journal of Occupational and Organizational Psychology, 66(4), 319-335.

Kray, L. J. \& Lind, E. A. (2002). The injustice of others: Social reports and the integration of others experiences in organizational justice judgment. Organizational Behavior and Human Decision Processes, 89, 906-924.

Lazarus, R. S., \& Folkman S. (1984). Stress, appraisal, and coping. New York: Springer.

Leung, K. (2005). How generalizable are justice effects across cultures? In J. Greenberg \& J. A. Colquitt (Eds.), Handbook of organizational justice (pp. 555-586). Mahwah, NJ: Erlbaum.

Locke, E. A., \& Latham, G. P. (2002). Building a practically useful theory of goal setting and task motivation: A 35-year odyssey. American Psychologist, 57(9), 705-717.

Morris, M. W., \& Leung, K. (2000). Justice for all? Progress in research on cultural variation in the psychology of distributive and procedural justice. Applied Psychology: An International Review, 49(1), 100-132.

Nunnally, J. C., \& Bernstein, I. H. (1994). Psychometric theory. McGraw-Hill.

OECD (2006). Higher education: Quality equity and efficiency. Report presented at the Meeting of OECD Education Ministers, Athens: June. [Electronic version]. Retrieved January 2007 from www.oecd.org 
Ogawa, K., \& Tansel, A. (2005). Education and labor market outcomes in Turkey. Journal of International Cooperation Studies, 12(3), 113-143.

Patterson, G. T. (2003). Examining the effects of coping and social support on work and life stress among police officers. Journal of Criminal Justice, 31(3), 215-226.

Shimatzu, A., \& Shutarou, K. (2003). Job stressors, coping and psychological distress among Japanese employees: Interplay between active and non-active coping. Work and Stress, 20(1), 38-51.

Snow, D., Swan, S. C., Raghavan, C., Connel, C. M., \& Kleines, I. (2003). The relationship of work stressors, coping and social support to psychological symptoms among female secretarial employees. Work and Stress, 17(3), 241-263.

Spector, P. E. (1986). Perceived control by employees: A meta-analysis of studies concerning autonomy and participation at work. Human Relations, 39, 1005-1016.

Spector, P. E., Cooper, C. L., \& Poelmans, S. (2004). A cross-national comparative study of work family stressors, working hours, and wellbeing: China and Latin America versus the Anglo world. Personnel Psychology, 57(1), 119-142.

Spector, P. E., \& Miles, D. (2001). Counterproductive work behavior (CWB) in response to job stressor and organizational justice: Some mediator and moderator tests for autonomy and emotions. Journal of Vocational Behavior, 59, 291-309.

Spector, P. E., Sanchez, J. I., Siu, O. L., Salgado, J., \& Ma, J. (2004). Eastern versus Western control beliefs at work: An investigation of secondary control, socioinstrumental control and work locus of control in China and the US. Applied Psychology: An International Review, 53(1), 38-60.

Stetz, T. A., Stetz, M. C., \& Bliese, P. D. (2006). The importance of self-efficacy in the moderating effects of social support on stressors-strain relationships. Work and Stress, 20(1), 49-59.

Thibaut, J., \& Walker, L. (1975). Procedural justice: A psychological analysis. Hillsdale, NJ: Erlbaum.

Trocki, K. F., \& Orioli, E. M. (1994). Gender differences in stress symptoms, stress producing contexts and coping strategies. In G. P. Keita \& J. J. Hurrel Jr. (Eds.), Job stress in a changing work force: Investigating gender, diversity and family issues (pp. 7-22). Washington DC: American Psychological Association.

Turkish Association for Education. (2005). Türkiye'de Üniversite Giris Sistemi Arastirmasi ve Çözüm Önerileri [Turkish university admissions system: Exploration and recommendations]. Ankara: TED.

van Daalen, G., Willemsen, T. M., \& Sanders, K. (2006). Reducing work-family conflict through different sources of social support. Journal of Vocational Behavior, 69(3), 462-476.

Van den Bos, K. (2003). On the subjective quality of social justice: The role of affect as information in the psychology of justice judgments. Journal of Personality and Social Psychology, 85(3), 482-498.

Van den Bos, K., Heuven, E., Burger, E., \& van Veldhuizen, M. (2006). Uncertainty management after reorganizations: The ameliorative effect of outcome fairness on job uncertainty. In R. Finkelstein \& D. Truchot (Eds.), Special Issue on Social Justice. International Review of Social Psychology, 19(1), 112-141.

Van den Bos, K., \& Lind, E. A. (2002). Uncertainty management by means of fairness judgments. In M. P. Zanna (Ed.), Advances in experimental social psychology (Vol. 34, pp. 1-60). San Diego, CA: Academic Press.

Vermunt, R., \& Steensma, H. (2005). How can justice be used to manage stress in organizations? In J. Greenberg \& J. A. Colquitt (Eds.), Handbook of organizational justice (pp. 383-411). Mahwah, NJ: Erlbaum.

Vitaliano, P., Russo, J., Carr, J. E., Maiuro, R. D., \& Becker, J. (1985). The Ways of Coping Checklist: Revision, and psychometric properties. Multivariate Behavioral Research, 20, 3-26. 
Yamaguchi, I. (2005). Interpersonal communication tactics and procedural justice for uncertainty management of Japanese workers. Journal of Business Communication, 42(2), 168-194.

Zellars, K. L., Liu, Y., Bratton, V., Brymer, R., \& Perrewé, P. L. (2004). An examination of the dysfunctional consequences of organizational injustice and escapist coping. Journal of Managerial Issues, 16(4), 528-544. 